\title{
Negative Ion Beam Emittance Calculations
}

\author{
M. Turek ${ }^{1}$, P. Węgierek ${ }^{2}$ \\ ${ }^{1}$ Institute of Physics, Maria Curie-Sklodowska University in Lublin, \\ pl. M.Curie-Sklodowskiej 1, 20-031 Lublin, Poland \\ ${ }^{2}$ Lublin University of Technology, \\ Nadbystrzycka str., 38A, Lublin 20-618, Poland
}

Received 14.01.2020

Accepted for publication 28.02.2020

\begin{abstract}
Computer simulations are commonly used to support design and optimisation of powerful negative ion sources for the needs of future thermonuclear reactors like e.g. ITER. The aim of the paper was to study changes of produced beam quality (described by its emittance and brightness) with the geometry of the extraction system as well as extraction voltage.

A two-dimensional Particle-in-Cell (PIC) method based code was applied to model $\mathrm{H}^{-}$ions and electrons extraction from the ion source plasma chamber through the opening with bevelled surface. The root-meansquare emittance of the extracted beam was calculated according to Chasman and Lapostolle approach. Ion beam phase space portraits were also presented to enrich the discussion.

Growth of ion (electron) beam emittance was observed both with the increasing radius of the extraction opening and the inclination of its bevelled surfaces. This degradation of beam quality is partially balanced by increasing extracted $\mathrm{H}^{-}$ion current. On the other hand, increasing length of the extraction channel improves the beam quality.

It was demonstrated that for wider extraction opening the $\mathrm{H}^{-}$ion beam consist of two parts coming form the two different regions of the chamber. According to calculated beam brightness the optimal wall inclination was found to be near $26^{\circ}$ in the studied case. The decrease of the beam emittance saturates for larger channel length values. In the considered case the optimal channel length was $h=1.7 \mathrm{~mm}$. The evolution of ion beam emittance and brightness shows that the best beam quality is achieved for extraction voltages between $0.5 \mathrm{kV}$ and $2 \mathrm{kV}$.
\end{abstract}

Keywords: ion beam, emittance, aperture.

DOI: $10.21122 / 2220-9506-2020-11-1-42-52$

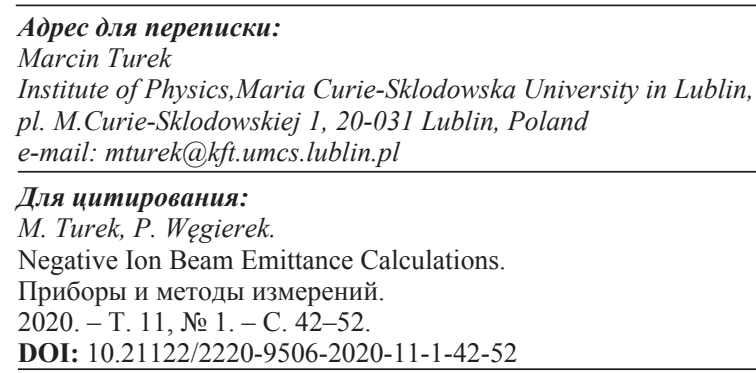

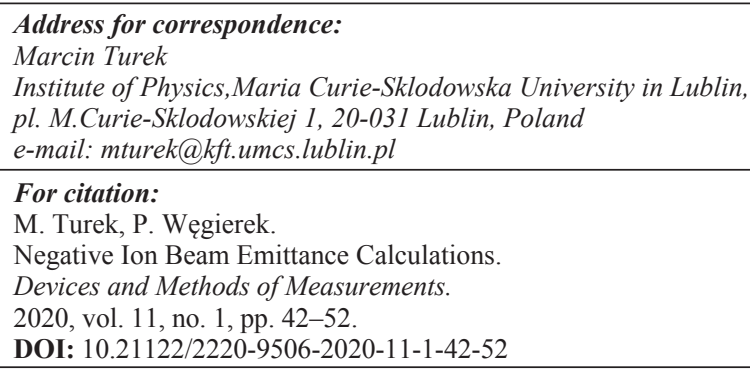




\title{
Расчёт эмиттанса пучка отрицательных ионов
}

\author{
М. Турек ${ }^{1}$, П. Венгерек ${ }^{2}$ \\ ${ }^{1}$ Институт физики, Университет имени Марии Кюри-Склодовской в Люблине, \\ пл. имени М. Кюри-Складовской, 1, г. Люблин 20-031, Польша \\ ${ }^{2}$ Люблинский технический университет, \\ ул. Надбыстриџкая 38А, г. Люблин 20-618, Польша
}

Поступила 14.01.2020

Принята к печати 28.02.2020

Компьютерное моделирование находит широкое применение в разработке и оптимизации мощных источников отрицательных ионов для будущих термоядерных реакторов, в частности, ITER. Целью настоящей работы являлось изучение изменений качества генерируемого пучка (характеризуемого параметрами эмиттанса и яркости) в зависимости от геометрии вытяжной системы и выходного напряжения.

Для моделирования извлечения ионов $\mathrm{H}^{-}$и электронов из плазменной камеры источника ионов через канал со скошенной поверхностью использовался двумерный метод частиц в ячейке (PIC). Среднеквадратическое значение эмиттанса извлечённого пучка рассчитывалось на основе подхода Часмана и Лапостолле. Дополнительно приводятся ионно-лучевые фазовые пространственные изображения ионного пучка.

Рост эмиттанса ионного (электронного) пучка наблюдался при увеличении как радиуса вытяжного канала, так и наклона его скошенной поверхности. Данное ухудшение качества пучка частично компенсируется увеличением ионным током $\mathrm{H}^{-}$. С другой стороны, увеличение длины вытяжного канала повышает качество пучка.

Показано, что в случае большей ширины вытяжного канала пучок ионов $\mathrm{H}^{-}$включает в себя две составляющих, исходящих из двух различных областей камеры. Из результатов расчёта яркости пучка следует, что оптимальный угол наклона стенки канала для рассматриваемого случая составляет $26^{\circ}$. Уменьшение эмиттанса пучка достигает насыщения при бо́льших значениях длины канала. В рассмотренном случае оптимальная длина канала составила $h=1,7$ мм. Эволюция эмиттанса и яркости ионного пучка показывает, что наилучшее качество пучка достигается при выходных напряжениях от 0,5 кВ до 2 кВ.

Ключевые слова: ионный пучок, эммиттанс, апертура.

DOI: $10.21122 / 2220-9506-2020-11-1-42-52$

\author{
Адрес для переписки: \\ Marcin Turek \\ Institute of Physics, Maria Curie-Sklodowska University in Lublin, \\ pl. M.Curie-Sklodowskiej 1, 20-031 Lublin, Poland \\ e-mail:mturek@kft.umcs.lublin.pl




\section{Introduction}

Powerful negative ion sources are cornerstones of neutral beam injection (NBI) devices [1] intended as one of the three basic heating and current drive systems developed for ITER that aims at achieving fusion power of $250 \mathrm{MW}$ with fusion gain 5 during an advanced scenario 1 hour cycle. The ITER includes two neutral beam injectors [2], each of them capable of delivering approximately $16 \mathrm{MW}$. During the development of the NBI system the large-area multi-driver RF ion source developed at IPP Garching [3] proved to be a reference device. A detailed description of the ion source and its principle of operation could be found in [4].

Numerical modeling of ion production, ion beam extraction and transport for decades goes hand in hand with design and optimisation of ion beam based system, so was in the case of considered NBI system. Several numerical models of negative ion beam production and extraction were reported over the years [5-11], either focusing on a precise description o plasma and ion beam behavior near a single aperture of the plasma grid, or presenting a more holistic approach to the problem. Reviews, sometimes critical, of the state-of-the-art approaches could be found in [12-14]. A special attention was paid to the effects of a transverse magnetic fields interaction on both ion and electron extraction, including stopping of co-extracted electrons and enhancing the extracted negative ion current $[5,6,15-16]$, which was also shown in experiments $[17,18]$.

In the current paper a two-dimensional, Particlein-Cell method based numerical model of negative ion source is employed to investigate ion beam quality quantitatively measured by its emittance. The numerical model was presented in [19-21] - it assumes that the most intensive production of $\mathrm{H}^{-}$ ions takes place on caesiated surface of the plasmafacing electrodes (also at the beveled surfaces of the extraction aperture), in the process of conversion of neutral atoms hitting these surfaces. The overall flowchart of the simulation is very similar to that applied in the case of 3D model considered in [16]. In the paper results of emittance calculations for different extraction channel geometries are presented and discussed. Changes of both ion beam emittance and beam brightness with extraction aperture wall inclination, extraction channel radius and its length are considered. A special attention is paid to emittance evolution with extraction voltage. Changes of the beam quality are also illustrated by its phase space portraits. Ion beam parameters are compared to that obtained for the co-extracted electron beam. Also the brief description of the model and introduction to the concept of emittance is given for self-completeness.

\section{Ion beam emittance}

A brief description of the concept of beam emittance is given below for the sake of completeness. Let us suppose that we consider a beam formed by $N$ particles, which could be represented by a single point in $6 \mathrm{~N}$-dimensional phase space (three coordinates $x, y, z$, and corresponding momenta $p_{x}$, $\left.p_{y}, p_{z}\right)$. As an alternative, one may follow $N$ points in 6-dimensional phase space. Generally, emittance is a 6-dimensional volume of such phase space restricted by a 5-dimensional surface of some (arbitrary chosen) constant phase space density [22]. Before some more practical description of this magnitude used in particle beam physics is given, some assumptions should be made. As long as one momentum is the dominant one, i. e. all particles move, more or less, in the same direction (without losing of generality along the $z$ axis) it is justified to separate their longitudinal and transversal motion. As it has been already mentioned, the momentum along the beam axis $\left(p_{z}\right)$ is much greater than the transversal one. Thus it is common approach to switch to orbital angles defined as:

$$
x^{\prime}=\frac{p_{x}}{p_{z}} \text { and } \quad y^{\prime}=\frac{p_{y}}{p_{z}} .
$$

Similarly to the above-mentioned general case, the fractional (transversal) emittances in the so-called trace space are defined as the surfaces of the ellipses containing some part of the beam (close but usually not equal to $100 \%$ ) in the both ( $x x^{\prime}$ and $\left.y y^{\prime}\right)$ positionangle subspaces. Note, that elliptic shape of the constraining surface fits very well to the commonly used bi-Gaussian approximation of the phase space distribution of ion beam. The surface of the ellipsis could be obtained using statistical approach, which is usually more suitable for computer code:

$$
\begin{aligned}
& \varepsilon_{x, r m s}=\sqrt{\left\langle x^{2}\right\rangle\left\langle x^{\prime 2}\right\rangle-\left\langle x x^{\prime}\right\rangle^{2}} \text { and } \\
& \varepsilon_{y, r m s}=\sqrt{\left\langle y^{2}\right\rangle\left\langle y^{\prime 2}\right\rangle-\left\langle y y^{\prime}\right\rangle^{2}},
\end{aligned}
$$

where brackets mean generally second central moment of the particle distribution [23], which is in symmetric cases the same as the average over the total ensemble. The concept of the statistical (root 
mean square) emittance was introduced by Chasman and Lapostolle and was refined in later papers [23]. It should be mentioned here that some authors suggest rescaling of the emittance e. $g$. by the factor $4 \pi$.

Due to the fact that in the presented paper a two-dimensional model is under consideration, a transversal $\mathrm{rms}$ emittance is calculated as:

$\varepsilon_{r m s}=\sqrt{\left\langle y^{2}\right\rangle\left\langle y^{\prime 2}\right\rangle-\left\langle y y^{\prime}\right\rangle^{2}}$

where $y^{\prime}$ - angle is re-defined according to formula:

$$
y^{\prime}=\frac{p_{y}}{p_{x}}
$$

as the ion beam is extracted along $x$ axis.

\section{Numerical model}

The PIC (Particle-In-Cell) approach based numerical model employed in the paper has been described in details in previous papers $[15,16]$. Some brief resume is given for the sake of completeness.

Two-dimensional model of an ionisation chamber of length $L=4.5 \mathrm{~mm}$ and width $5 \mathrm{~mm}$ with a flat extraction electrode on the negative extraction potential $V_{e x t}$ at the distance $\mathrm{d}$ from the extraction opening is considered. The schematic view of the simulation area is presented in Figure 1. $\mathrm{H}^{-}$ions and electrons are pulled out through a conical extraction channel. The geometry of the extraction aperture is determined by the channel length $h$ and its inner and outer radii $r_{i}$ and $r_{0}$. The area is discretised using a rectangular $160 \times 100$ grid (cell sizes are $\Delta x=\Delta y=0.05 \mathrm{~mm}$ ). The chamber is initially filled with $10^{7}$ pseudoparticles representing electrons and $\mathrm{H}^{+}$ions (equal numbers). Charge density of plasma is set to $10^{16} \mathrm{~m}^{-3}$ and its temperature is $k T=1 \mathrm{eV}$. The electrostatic potential distribution is found by solving the Poisson equation with boundary conditions imposed by electrodes using successive over-relaxation method (SOR), as in previous papers [15-16, 24].

Once the potential and charge distributions are found, the electric field in the grid points is derived. Pushing particles forward according to classical equations of motion is done using the Verlet method [25]. After that, new particle positions and velocities could be determined, making it possible to find the new charge density distribution. The whole cycle is repeated as long as necessary.

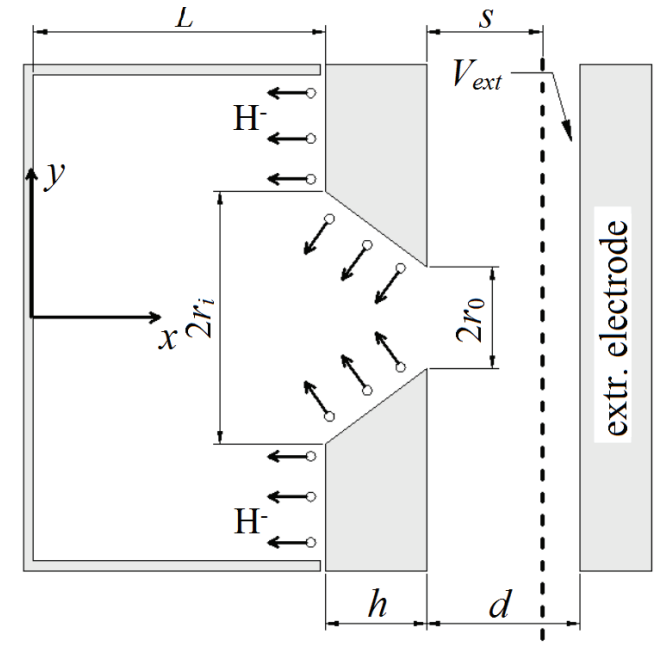

Figure 1-Schematic view of the simulation area. The plane for which emittance is calculated is marked with a dashed line

After some quasi-stationary state is achieved ( 20000 timesteps) negative hydrogen ions start to be injected into the chamber with the constant rate ( $N_{H-}$ per one timestep). These ions are ejected not only from the front wall but also from the beveled surfaces of the extraction aperture. Initial velocities of $\mathrm{H}^{-}$ions correspond to $k T=0.25 \mathrm{eV}$. The $\mathrm{H}^{-}$flux perpendicular to $x$ axis is the same for both inner wall and beveled opening in order to model the neutral atom -negative ion conversion that occurs on caesiated surfaces. Negative ion undergoes elastic collisions with other particles inside the chamber, which is realised using Monte Carlo method based binary collision approximation. The electron and ion curents are registered at the plane at the distance $s=1.5 \mathrm{~mm}$ from the extraction aperture (marked as dashed line in Figure 1). Positions and velocities of particles passing this plane are saved in order to calculate emittance values and present trace space portraits if necessary. The code registers also e.g. potential values in the chosen points of the ion source chamber, the number of negative ions and charge density as well as electrostatic potential distributions snapshots.

\section{Simulation results}

Some examples of general results of simulations are presented in Figure 2. Calculations were performed for $r_{0}=0.7 \mathrm{~mm}$ and $r_{i}=1.5 \mathrm{~mm}$ and $h=1 \mathrm{~mm}$. Extraction voltage was set to $V_{\text {ext }}=2 \mathrm{kV}$ while the distance between the electrode and extraction aperture was $d=2.5 \mathrm{~mm}$. The calculations were repeated 160000 times. The timestep was 
$0.2 \cdot 10^{-11} \mathrm{~s}$ in order to ensure simulation stability according to the Courant-Friedrichs-Lewy criterion.
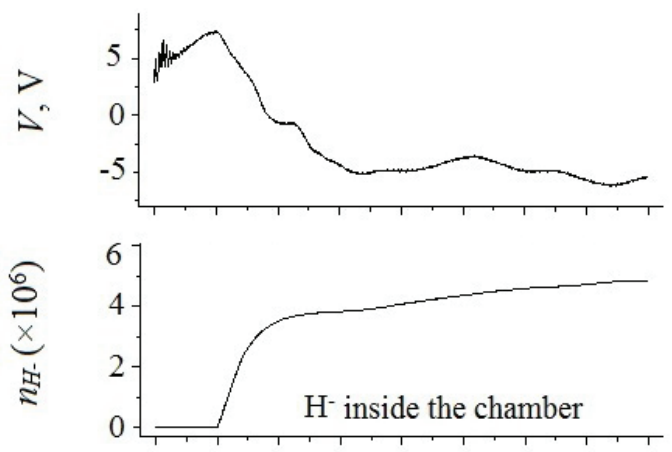

$a$
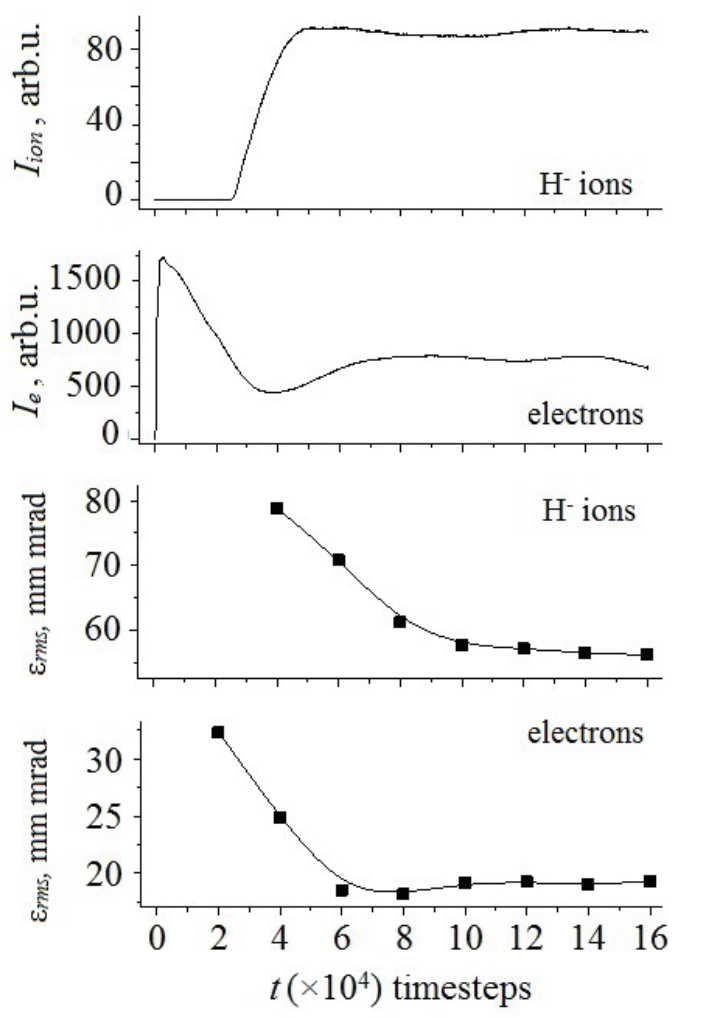

Figure 2 - Evolution of some chosen quantities during the simulation: $a$-potential $V$ inside the chamber; $b$ - the number of $\mathrm{H}^{-}$ions inside the chamber $n_{H-} ; c-$ the extracted $\mathrm{H}^{-}$current $I_{i o n} ; d$ - the extracted electron current $I_{e} ; e-\mathrm{H}^{-}$ ion beam emittance $\varepsilon_{r m s} ; f$-co-extracted electron beam emittance

Very fast potential oscillations disappear after $\sim 10000$ timesteps and $\mathrm{H}^{-}$ions injection begins after 20000 timesteps with the constant rate $N_{H_{-}}=300$ per $\Delta t$. As a result one observes lowering of the potential inside the chamber to $\approx-5 \mathrm{~V}$ after approximately 70000 timesteps. At the same time both extracted electron and ion current reach stable values. It should be noted that the number of negative ions in the chamber slowly increases up to $\approx 5 \cdot 10^{6}$. Emittance of extracted ion beam (and also co-extracted electron beam) is calculated every 20000 timesteps taking into account every particle extracted during that period. As one can see, initial values are rather high and decrease in time reaching equilibrium after 100000 timesteps. Emittance of ion beam is much higher in the case of negative ions, mostly due to the fact that a divergent $\mathrm{H}^{-}$beam consisting of two parts is formed, as was demonstrated in [21].

Figure 3 presents final rms emittance values obtained for different $r_{i}$ values and, hence, different slopes of the extraction channel walls. It should be $b$ kept in mind that inclination angle is given by:

$$
\operatorname{tg}(\alpha)=\frac{r_{i}-r_{0}}{h}
$$
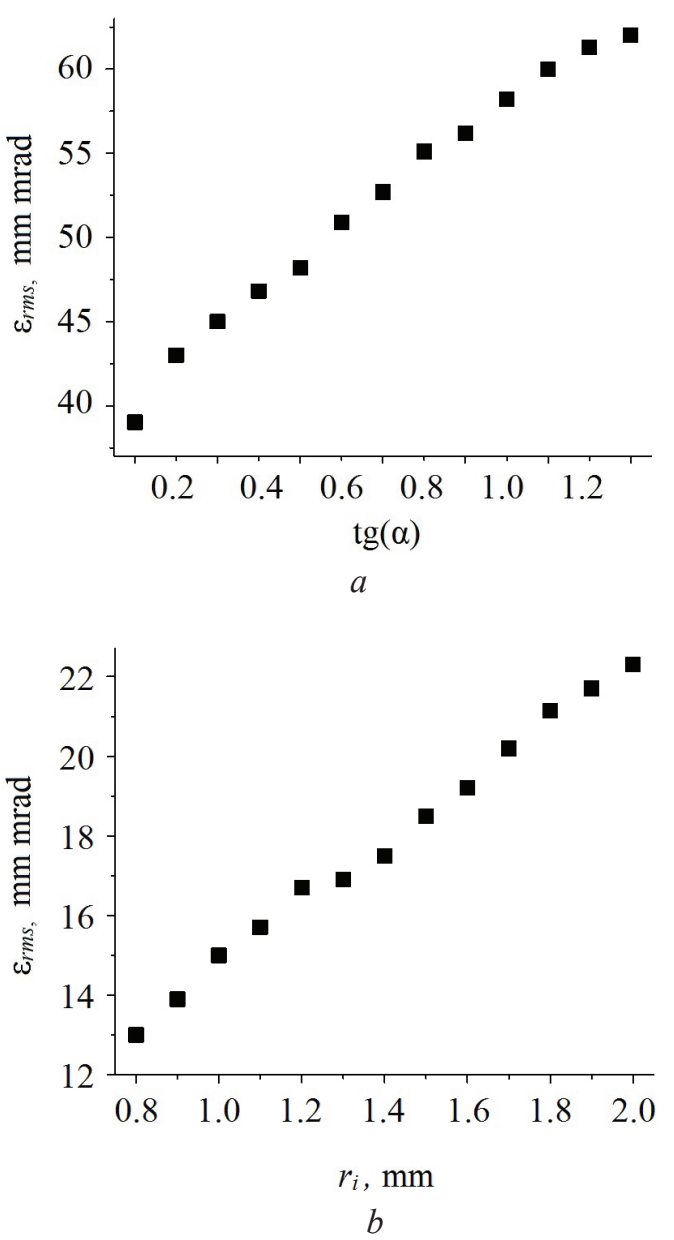

Figure 3 - Dependence of ion $(a)$ and electron $(b)$ emittance $\varepsilon_{r m s}$ on extraction channel wall inclination $\operatorname{tg}(\alpha)$ governed by $r_{i}$ radius (for $r_{0}=1.4 \mathrm{~mm}$ )

One can see that that $\varepsilon_{\text {rms }}$ increases almost linearly with $r_{i}$. It has little to do with emitting surface inclination, as the same effect is observed for electrons. As the extraction channel entrance becomes wider and wider, both ion and electron 
and ion beam become more and more divergent. If one, however, uses another figure of merit i.e. beam brightness understood as the ratio of the current and phase space volume:

$$
B=\frac{I}{\varepsilon_{r m s}^{2}},
$$

it could be seen (Figure 4) that optimal beam quality is achieved in the considered case for $r_{i}$ near $1.2 \mathrm{~mm}$, which corresponds to $\alpha$ close to $26^{\circ}$. This is due to the fact that extracted ion current grows very fast with inclination [21]. The optimal inclination angle is result of the two competing trends: increasing beam spread and current with $r_{i}$. On the other hand, brightness of the electron beam decreases with $r_{i}$ as the extraction from plasma volume is mostly limited by constant $r_{0}$.
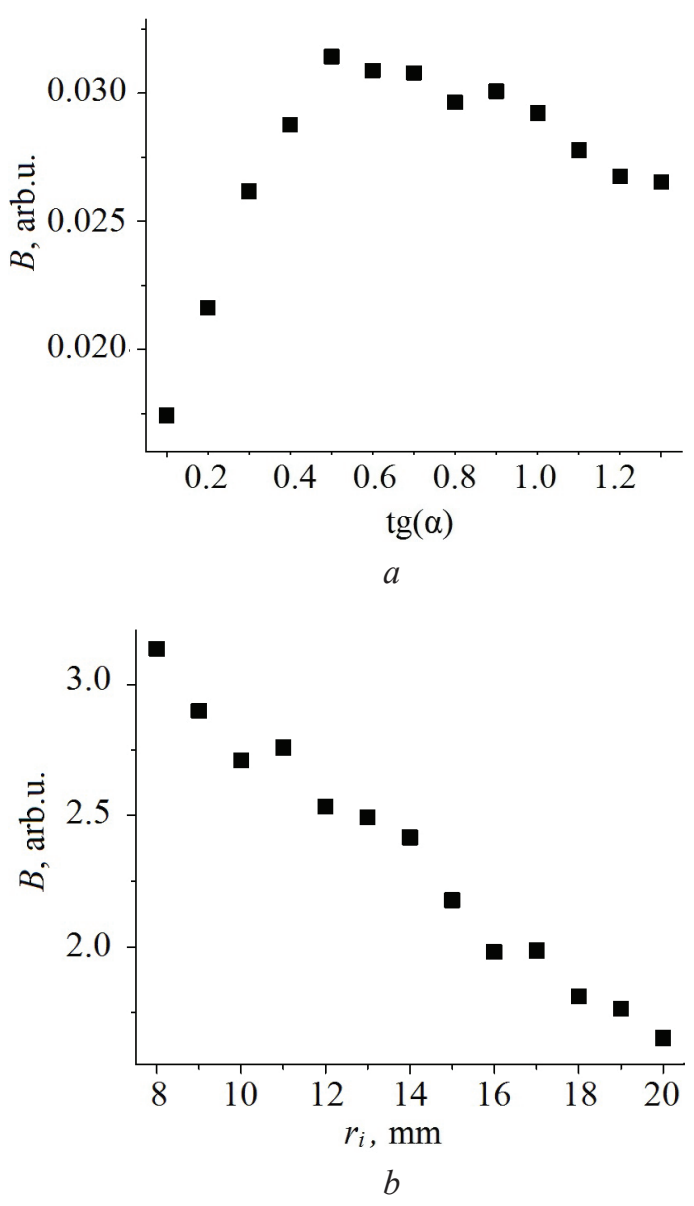

Figure 4-Brightness $B$ of ion and electron beams calculated for different values of $r_{i}$ (for $r_{0}=1.4 \mathrm{~mm}$ )

The change of the beam quality with the width of the extraction channel was also under investigation. Figure 5 presents evolution of emittance and brightness of negative ion beam with $r_{0}$ radius for the two different inclination angles. One can see that in both case emittance increases very fast with channel width, even by an order of the magnitude for larger inclination angle. Dependences of brightness on $r_{0}$ confirm that that more focused beams, characterised by reasonable current, are achieved for narrower extraction apertures with beveled walls (case 1). A change of the beam profile with $r_{0}$ is even better visible in trace space portraits shown in Figure 6. They were prepared using coordinates and velocities of all $\mathrm{H}^{-}$ions extracted during last 5000 timesteps of simulation. For narrow extraction channel a pattern typical for a single divergent beam could be seen. As the $r_{0}$ radius increases, the pattern changes: instead of a single elliptical spot one can see two o-shaped pattern formed by the two crescent structures, each of them corresponding to different part of the ion beam - one extracted from the upper and the other form lower surface of extraction channel. The change of the whole size of the trace space portrait depicts the increase of beam emittance in the presented case.
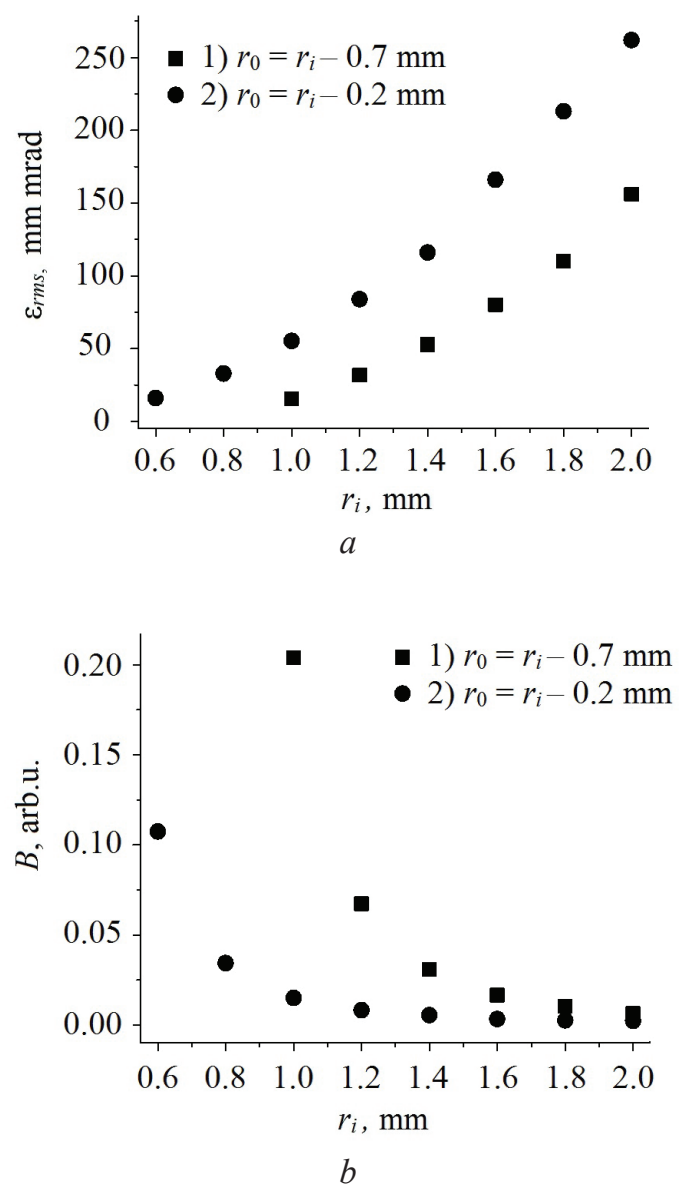

Figure 5 - Changes of emittance $\varepsilon_{r m s}(a)$ and brightness $B(b)$ with the extraction channel radius $r_{I}$ 


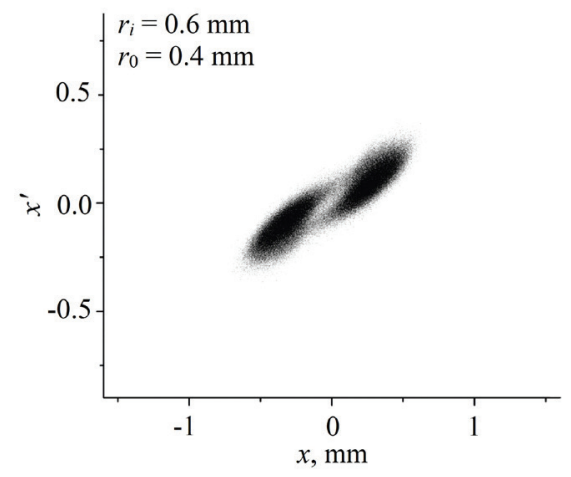

$a$

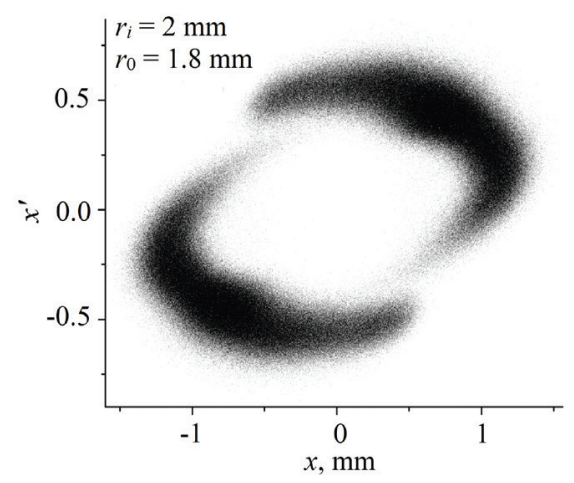

$b$

Figure 6 - Phase space portraits in $x-x^{\prime}$ subspace (positionangular velocity) of ion beams extracted through apertures of different radii

Figure 7 presents changes of the rms emittance of ion and electron beams calculated for different lengths of the extraction channel $h$ ( $r_{i}$ and $r_{0}$ radii were kept constant in this case). As one can see, the emittance of the negative ion beam decreases with $h$. However, for $\mathrm{H}^{-}$ions the effect is rather subtle - of order of $20 \%$ and saturation could be seen for larger $h$. The dependence of ion beam brightness is shown in Figure 8 confirms, that the optimal extraction channel length is near $1.7 \mathrm{~mm}$ in the considered case.

At the next stage the influence of the extraction voltage on the beam quality was investigated. Calculations were done for $V_{\text {ext }}$ up to $20 \mathrm{kV}$ and for $r_{i}=1.5 \mathrm{~mm}$ and $r_{0}=0.7 \mathrm{~mm}$.

As one can see in Figure 9 emittance of the negative ion beam is initially rather high, but it decreases very fast with $V_{\text {ext }}$ reaching minimum for $V_{\text {ext }}=500 \mathrm{kV}$, which could be considered as matching case from that point of view. For higher values of extraction voltage ion beam spread increases again and beam quality is poorer despite the higher extracted current.
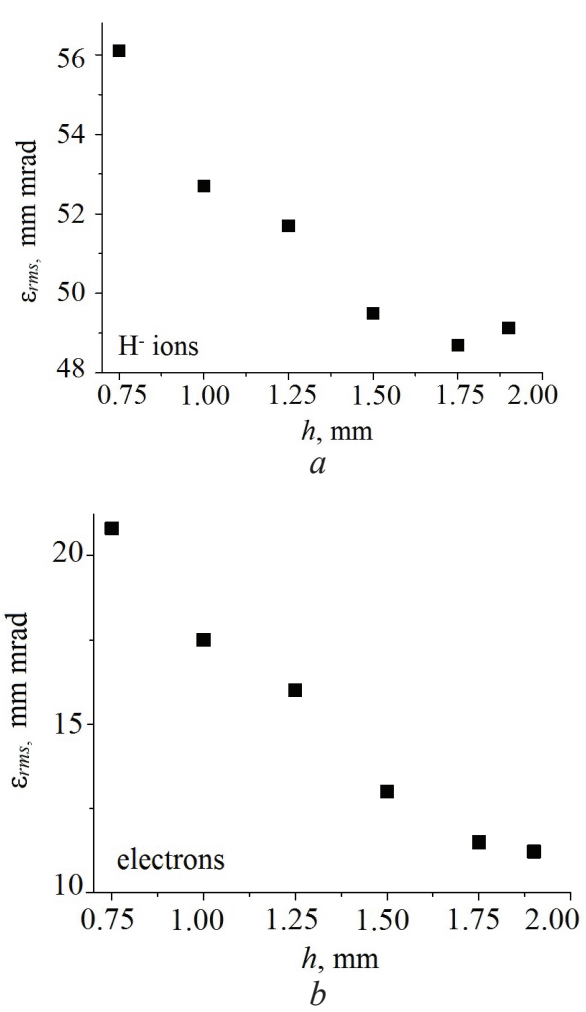

Figure 7 - Emittance $\varepsilon_{r m s}$ of ion $(a)$ and electron $(b)$ beams for different lengths of extraction channel. The case of $r_{i}=1.5 \mathrm{~mm}$ and $r_{0}=0.7$
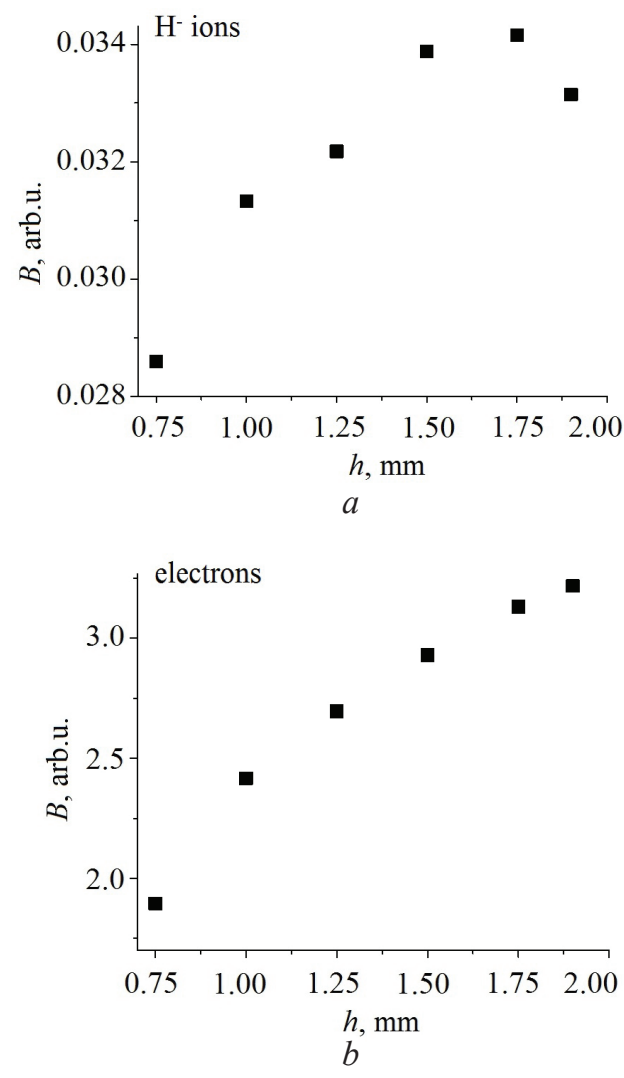

Figure 8 - Brightness $B$ of ion $(a)$ and electron $(b)$ beams as function of length $h$ of the extraction channel 

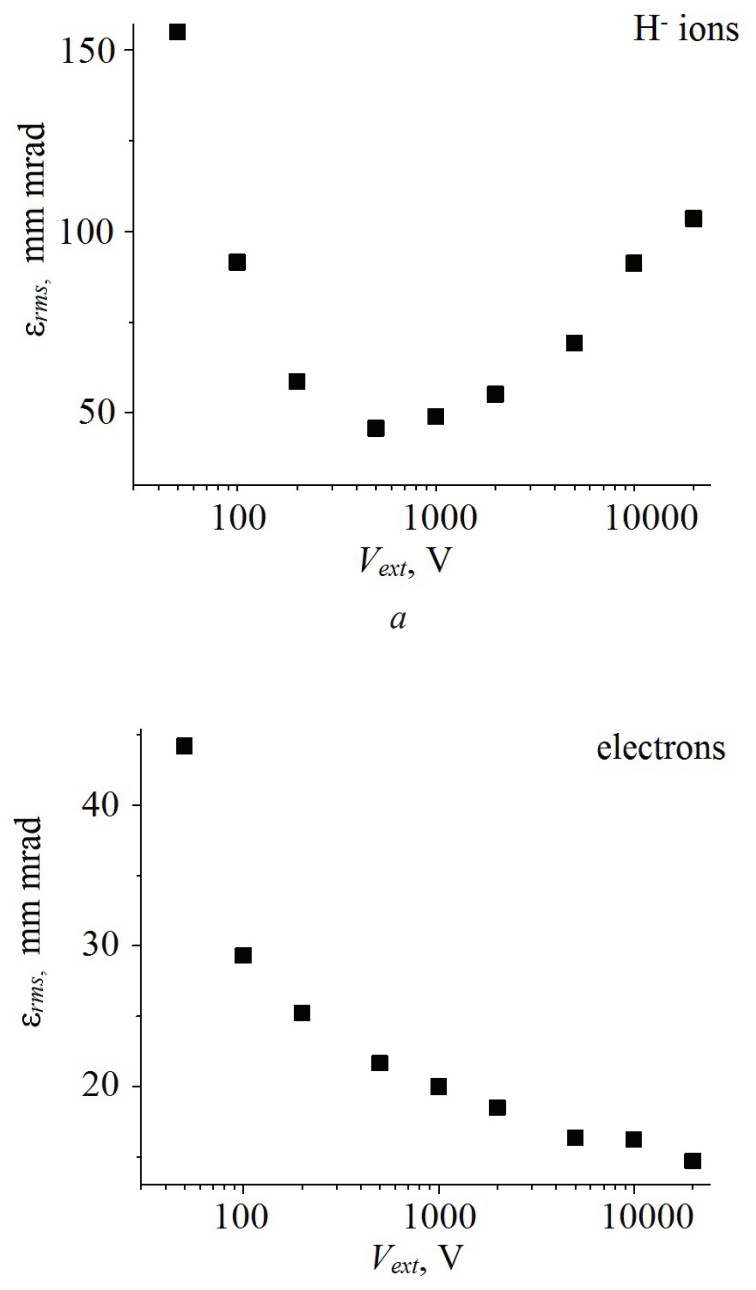

$b$

Figure 9-Changes of emittance $\varepsilon_{r m s}$ with extraction voltage $V_{\text {ext }}$. Results for negative ions $(a)$ and electrons $(b)$ in the case of $r_{i}=1.5 \mathrm{~mm}$ and $r_{0}=0.7 \mathrm{~mm}$

Calculated values of beam brightness are shown in Figure 10. Due to the fast increase of ion current with $V_{\text {ext }}[22,21]$ one can see that optimal brightness is achieved for $V_{e x t}=2 \mathrm{keV}$. As it was shown in that paper the shape of the negative ion beam changes substantially with $V_{\text {ext }}$. For lower $V_{\text {ext }}$ a single beam is formed, which is convergent right behind the extraction aperture. As phase space portrait (Figure 11) shows, the beam is divergent at the distance s form the source, forming two intersecting spots. However, for larger $V_{\text {ext }}$ near $2 \mathrm{keV}$ one can see two very distinct beamlets emitted from upper and lower walls of the extraction channel and pass one another in the middle of that channel (see Figure 11). Looking at the phase space portrait one can see that a) two distinct spots are visible - each of them corresponding to different beamlet and b) the beam is more divergent as the emittance ellipse is more inclined towards the abscissa axis. For even larger values of extraction voltage beamlets become parallel to ion source axis, the two-part beam becomes even more divergent. Emittance is two times larger than in the optimum. O-shaped pattern is formed at the phase space portrait due to non-linearity of forces acting near the extraction channel edges.
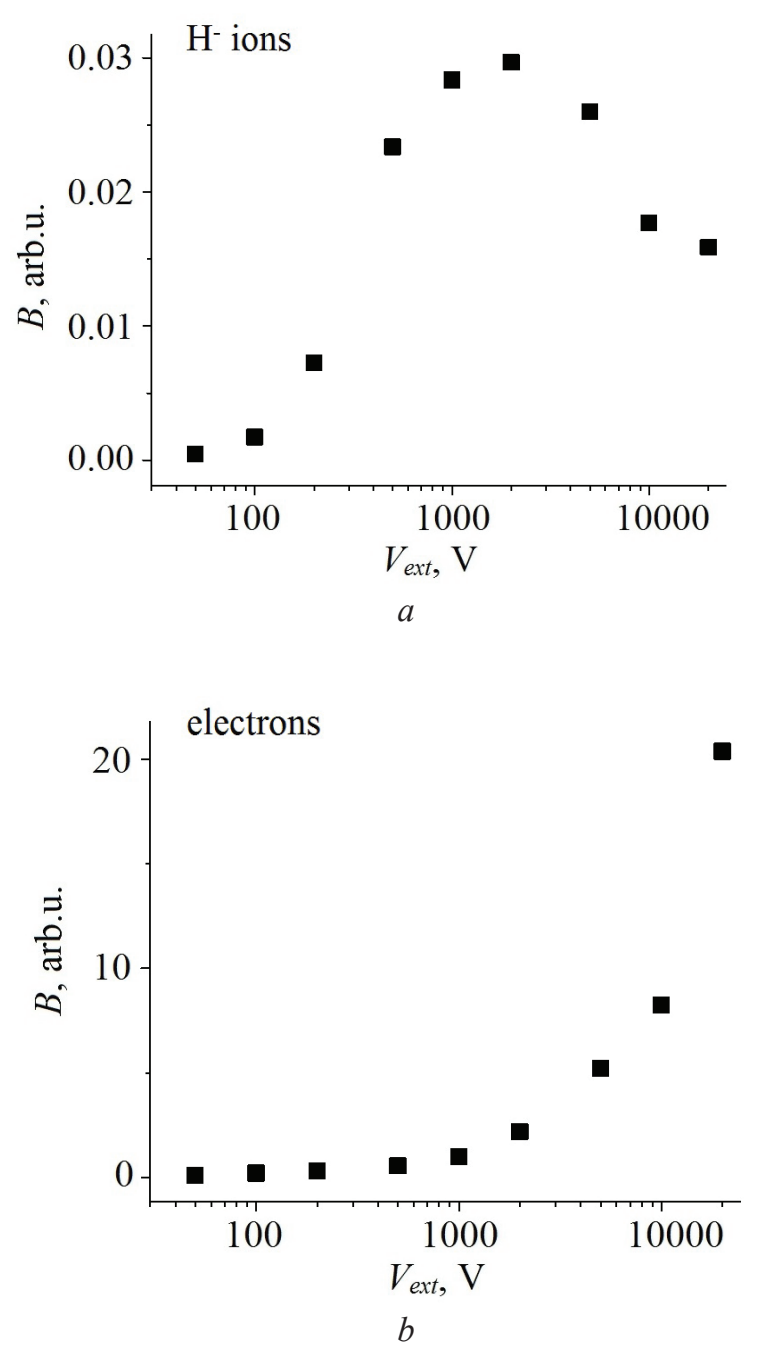

Figure 10-Changes of beam brightness $B$ with extraction voltage $V_{\text {ext }}$. Results for negative ions $(a)$ and electrons $(b)$

It should be noticed that the co-extracted electron beam emittance behaves in a different way. Emittance continuously decreases with $V_{\text {ext }}$ reaching values below $20 \mathrm{~mm}$ mrad for $V_{\text {ext }}$ larger than $1 \mathrm{keV}$. One should have in mind that high intensity of electron beam must be taken into account when filtering/damping systems for co-extracted electrons are designed. 

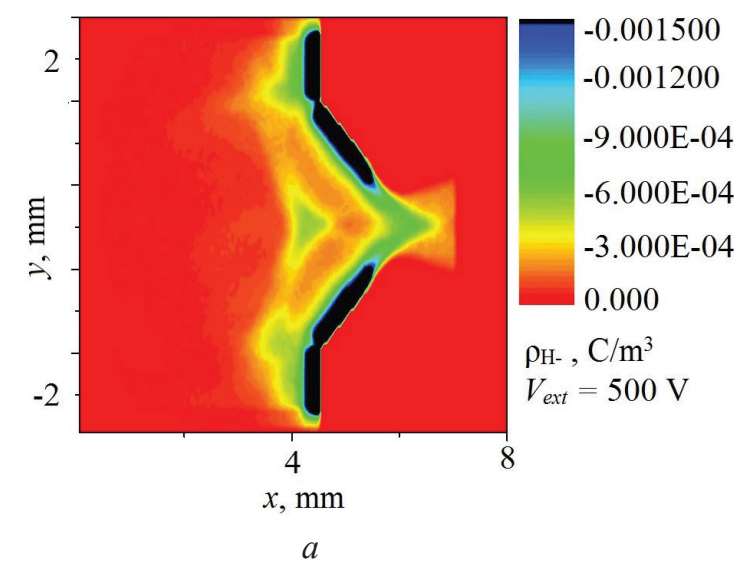

$a$
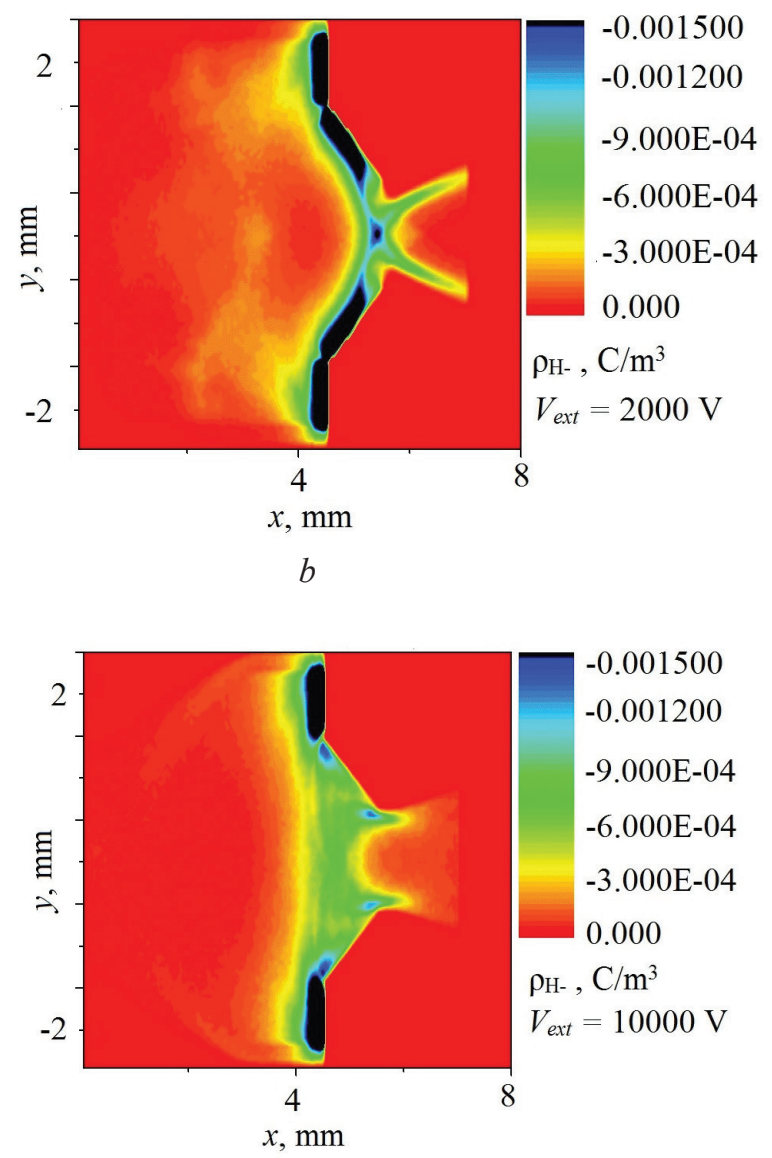

c

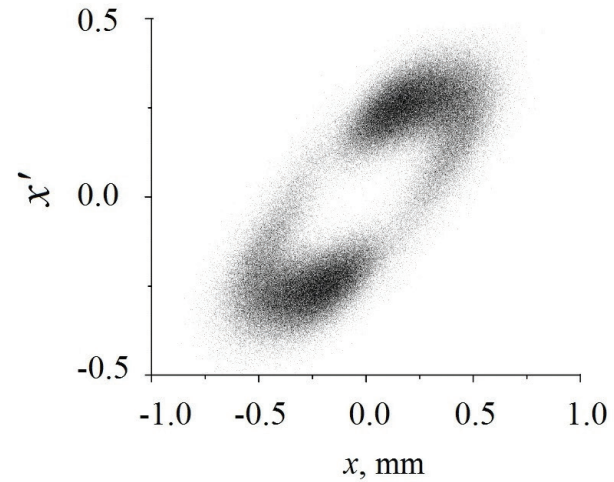

$d$

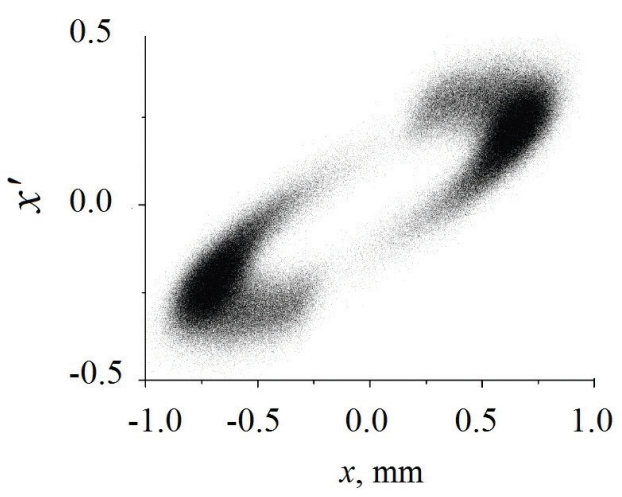

e

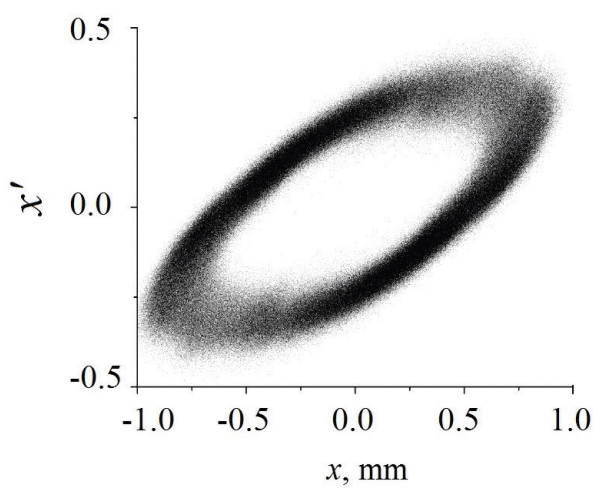

$f$

Figure $11-\mathrm{H}^{-}$charge density distributions $\rho_{\mathrm{H}-}$ and extracted ion beam phase space portraits (in $x-x^{\prime}$, position - angular velocity subspace) for different values of extraction voltage $V_{\text {ext }}$

\section{Conclusion}

Particle-in-Cell method based numerical model of negative ion production in neutral-to-ion surface conversion and negative ion beam extraction and formation were presented in the paper. It was shown that both electron ion beam emittance stabilises after $\sim 100000$ timesteps of simulation. As it was demonstrated in the previous paper, most of the extracted ions come from the chamfered walls of the extraction aperture. Hence, emittance of ion (and also electron) beam strongly depends on the wall inclination angle. Calculation of ion beam brightness shows that the optimal inclination is near the angle of $26^{\circ}$. On the other hand, brightness of the co-extracted electron beam decreases with $r_{i}$. 
It was also checked that ion beam emittance rapidly increases with extraction aperture radius, and this effect was observed for different inclination angles. Phase space portraits of the ion beam show that the wider is the extraction channel, the better it is visible that negative ion consist of two parts, each of them coming out of different region of the plasmafacing electrode.

It was found that the beam quality generally increases with extraction channel length $h$. However, a kind of saturation could be observed and in the considered case optimum was observed for $h=1.7 \mathrm{~mm}$. The evolution of ion beam emittance with extraction voltage was checked out. It was demonstrated that the $\mathrm{H}^{-}$beam emittance initially decreases fast with $V_{e x t}$, and matching case is achieved for $V_{\text {ext }}=0.5 \mathrm{kV}$. As the extracted ion current grows very fast with $V_{\text {ext }}$, and despite the fact that emittance increases, the highest beam brightness was achieved for $V_{\text {ext }}=2 \mathrm{kV}$. Phase space portraits and $\mathrm{H}^{-}$charge density distribution snapshots illustrate changes of $\mathrm{H}^{-}$ion beam shape with $V_{e x t}$.

\section{Acknowledgments}

The research was co-funded by th Plenipotent Representative of the Government of the Republic of Poland at JINR Dubna in the frame of the project № 75/07/2020.

\section{References}

1. Singh M.J., Boilson D., Polevoi A.R., Oikawa T., Mitteau R. Heating neutral beams for ITER: negative ion sources to tune fusion plasmas. New J. Phys., 2017, vol. 19 , iss. 5 , pp. 055004.

DOI: $10.1088 / 1367-2630 / \mathrm{aa} 639 \mathrm{~d}$

2. Hemsworth R., Decamps H., Graceffa J., Schunke B., Tanaka M., Dremel M., Tanga A., De Esch H.P.L., Geli F., Milnes J., Inoue T., Marcuzzi D., Sonato P., Zaccaria P. Status of the ITER heating neutral beam system. Nucl. Fusion, 2009, vol 49, no. 4, pp. 045006.

DOI: $10.1088 / 0029-5515 / 49 / 4 / 045006$

3. Kraus W., Fantz U., Franzen P., Fröschle M., Heinemann B., Riedl R., Wünderlich D. The development of the radio frequency driven negative ion source for neutral beam injectors. Rev. Sci. Instrum., 2012, vol. 83, pp. 02B104. DOI: 10.1063/1.3662957

4. Heinemann B., Fantz U., Kraus W., Schiesko L., Wimmer C., Wünderlich D., Bonomo F., Fröschle M., Nocentini R., Riedl R. Towards large and powerful radio frequency driven negative ion sources for fusion. New J.
Phys., 2017, vol. 19, iss. 1, pp. 015001.

DOI: $10.1088 / 1367-2630 /$ aa520c

5. Mochalskyy S., Lifschitz A.F., Minea T. Extracted current saturation in negative ion sources. J. Appl. Phys., 2012, vol. 111, no. 11, pp. 113303.

DOI: $10.1063 / 1.4727969$

6. Mochalskyy S., Wuenderlich D., Fantz U., Franzen P., Minea T. Towards a realistic 3D simulation of the extraction region in ITER NBI relevant ion source. Nucl. Fusion, 2015, vol. 55, no. 3, pp. 033011.

7. Fubiani G., Boeuf J.P. Three-dimensional modeling of a negative ion source with a magnetic filter: impact of biasing the plasma electrode on the plasma asymmetry. Plasma Sources Sci. Technol., 2015, vol. 24, iss. 5, pp. 055001. DOI: 10.1088/0963-0252/24/5/055001

8. Nishioka S., Goto I., Miyamoto K., Hatayama A., Fukano A. Study of ion-ion plasma formation in negative ion sources by a three-dimensional in real space and three-dimensional in velocity space particle in cell model. J. Appl. Phys., 2016, vol. 119, iss. 2, pp. 023302.

DOI: $10.1063 / 1.4939467$

9. Revel A., Mochalskyy S., Montellano I.M., Fantz U., Minea T. Massive parallel 3D PIC simulation of negative ion extraction. J. Appl. Phys., 2017, vol. 122, iss. 10, pp. 103302. DOI: 10.1063/1.5001397

10. Fubiani G., Garrigues L., Hagelaar G., Kohen N., Boeuf J.P. Modeling of plasma transport and negative ion extraction in a magnetized radio-frequency plasma source. New J. of Phys., 2017, vol. 19, pp. 015002.

DOI: $10.1088 / 1367-2630 / 19 / 1 / 015002$

11. Taccogna F., Minelli P., Longo S. Threedimensional structure of the extraction region of a hybrid negative ion source. Plasma Sources Sci. Technol., 2013, vol. 22 , no. 4 , pp. 045019.

DOI: $10.1088 / 0963-0252 / 22 / 4 / 045019$

12. Wunderlich D., Mochalskyy S., Montellano I.M., Revel A. Review of particle-in-cell modeling for the extraction region of large negative hydrogen ion sources for fusion. Rev. Sci. Instrum., 2018, vol. 89, iss. 5, pp. 052001. DOI: 10.1063/1.5011799

13. Taccogna F., Minelli P. PIC modeling of negative ion sources for fusion. New J. Phys., 2017, vol. 19, iss. 1, pp. 015012. DOI: 10.1088/1367-2630/aa5305

14. Garrigues L., Fubiani G., Boeuf J.P. Negative ion extraction via particle simulation for fusion: critical assessment of recent contributions. Nucl. Fusion, 2017, vol. 57 , no. 1 , pp. 014003 .

DOI: $10.1088 / 0029-5515 / 57 / 1 / 014003$

15. Sakurabayashi T., Hatayama A., Bacal M. Effects of a weak transverse magnetic field on negative ion transport in negative ion sources. J. Appl. Phys., 2004, vol. 95, iss. 8, pp. 3937-3942. DOI: 10.1063/1.1682684

16. Turek M., Sielanko J. Simulations of negative ion extraction from a multi-aperture ion source in the presence 
of the magnetic filter. Vacuum, 2009, vol. 83, pp. S256S259. DOI: 10.1016/j.vacuum.2009.01.076

17. Bacal M., Bruneteau J., Devynck P. Method for extracting volume produced negative ions. Rev. Sci. Instrum. 1988, vol. 59, pp. 2152-2157.

DOI: $10.1063 / 1.1139978$

18. Wünderlich D., Kraus W., Fröschle M., Riedl R., Fantz U., Heinemann B., the NNBI team. Influence of the magnetic field topology on the performance of the large area negative hydrogen ion source test facility ELISE. Plasma Phys. and Control. Fusion, 2016, vol. 58, pp. 125005. DOI: 10.1088/0741-3335/58/12/125005

19. Turek M. Two-Dimensional Simulations of $\mathrm{H}^{-}$ Ions Extraction. Acta Phys. Pol. A, 2017, vol. 132, iss. 2, pp. 254-258.

DOI: $10.12693 /$ APhysPolA.132.254

20. Turek M. PIC simulations of plasma inside the negative ion source. Przegl. Elektrotechniczny, 2016, vol. 92(8), pp. 162-165.|

21. Turek M. Negative Ion Beam Production in an Ion Source with Chamfered Extraction Opening. Acta Phys. Pol., 2019, vol. 136, pp. 322-328.

22. Floettmann K. Some basic features of the beam emittance. Phys. Rev. Spec. Topics - Accel. and Beams 2003, vol. 6, pp. 034202.

DOI: $10.1103 /$ PhysRevSTAB.6.034202

23. Brown I.G. (ed.) The Physics and Technology of Ion Sources. Wiley, Weinheim, 2004.

24. Turek M., Drozdziel A., Pyszniak K., Prucnal S., Żuk J. Ion source with an evaporator heated by arc discharge. Experiment and computer simulations. Przegl. Elektrotechniczny, 2010, vol. 86, pp. 193-196.

25. Vesely F. Computational Physics: An Introduction, Springer Science \& Business Media, 2001. 